\title{
Metastatic (Advanced) Prostate Cancer Resistant to Castration: The Time before Resistance Development and Therapeutic Measures Undertaken in Cote d'Ivoire
}

\author{
Kouassi Kouamé Konan Yvon*, Touré Moctar, Séka Evrard Narcisse, Oumou Kimso, \\ Traoré Kadjatou, Odo Bitti Addé, Traoré Asmaho Danielle, Kagambega Arsène Gaëtan, \\ Adoubi Innocent
}

Oncology Department of the Treichville University Hospital, Abidjan, Cote d'Ivoire

Email: *yvonkouassi@gmail.com

How to cite this paper: Yvon, K.K.K., Moctar, T., Narcisse, S.E., Kimso, O., Kadjatou, T., Addé, O.B., Danielle, T.A., Gaëtan, K.A. and Innocent, A. (2018) Metastatic (Advanced) Prostate Cancer Resistant to Castration: The Time before Resistance Development and Therapeutic Measures Undertaken in Cote d'Ivoire. Journal of Cancer Therapy, 9, 955-961.

https://doi.org/10.4236/jct.2018.912079

Received: September 25, 2018

Accepted: December 7, 2018

Published: December 10, 2018

Copyright (ㅇ 2018 by authors and Scientific Research Publishing Inc. This work is licensed under the Creative Commons Attribution International License (CC BY 4.0).

http://creativecommons.org/licenses/by/4.0/

\begin{abstract}
Objective: Contribute to improving care for prostate cancer patients in Cote d'Ivoire by identifying the average time before the development of the hormone-resistance and inherent therapeutic strategies. Patients and Method: It was a retro and prospective study over three years performed at the University Teaching Hospital of Treichville in Abidjan. 84 patients with metastatic prostate adenocarcinoma and resistant to hormone therapy were involved in the study. The analysis of clinical records enabled us to integrate different parameters in our study. Results: Our patients were relatively young (an average age of 61 years) and most of them belonged to the middle socio-economic class (50\%). The resistance occurred within an average period of 9 months. The mixing of Docetaxel and Prednisone chemotherapy was the most used method of treatment (70\% of cases). However, few patients (9.5\%) received Abiraterone Acetate. Digestive and hematologic toxicities were noticed but they could be controlled by inherent treatment or disappear spontaneously. After nine months of treatment, $54.24 \%$ of patients who received specific treatment were alive, but high rates of mortality were observed as for patients who were only treated symptomatically. Conclusion: The relatively short average time before the development of hormone-resistance shows the aggressiveness of prostate adenocarcinoma from black Africans. The main therapeutic standard in our context remains Taxane-based chemotherapy with a good and fair tolerance.
\end{abstract}

\section{Keywords}

Cancer, Prostate, Occurrence Time, Resistance 


\section{Introduction}

In sub-Saharan Africa in general and Cote d'Ivoire in particular, prostate cancer is most often diagnosed in metastatic stage [1] [2]. It is a hormone dependant cancer (androgen dependant) [3]. A better knowledge of prostate cancer oncogenesis has led to an efficient codification of its therapeutic strategy. Thus, hormonotherapy based on whether chemical or surgical method remains the therapeutic standard of the metastatic forms [4]. However, the development of resistance to this castration (showing a biological rise of the PSA levels after a stabilization period during treatment with LH-RH agonist or pulpectomy) is widespread and it occurs within a period from 24 to 36 months based on western series data [5] [6].

In our daily practice, a limited number of data (except observation) not only on this average time before the development of resistance but also the accessibility of our patients to the different treatments are available [7].

The general objective of this work was to contribute to improving the management of the prostate cancers in general and particularly the resistance to the castration in the Ivorian environment. Thus, the specific objective is to identify the average time before the development of hormone-resistance and determine the resulting therapeutic strategies.

\section{Patients and Method}

This is both retro and prospective study over three years (January 01, 2014-December 31, 2016). This study was carried out in the Department of Oncology of the University Teaching Hospital of Treichville in Abidjan and it involved 84 metastatic prostate adenocarcinoma patients with positive histological report. These patients were under confirmed androgen blocking treatment. Castration resistance in patient under hormone therapy was defined as the one with testosterone $<0.50 \mathrm{ng} / \mathrm{ml}$ with increasing PSA level with or without symptoms. The sample population was both in-patients and out-patient from the Oncology Department of Treichville University Teaching Hospital.

As for the retrospective study, data collection was based on the analysis of clinical records and the results of prostate biopsies histopathologic examinations reports. Concerning prospective study, interviews and physical examination have helped to highlight the characteristics of the initial hormonal treatment (Type, date of starting treatment) and the presence or not of functional signs. At the paraclinical level, a pre-therapeutic examination including the disease activity index (thoracic-abdominal-pelvic CT scan, abdominal-pelvic MRI) and the patient check-up (complete blood count, Creatinine, Transaminases, blood sugar level) were systematically realized.

These check-ups have helped to confirm whether or not the presence of other metastatic sites and minimize possible toxicities of the selected therapeutic methods. These therapies were administered either orally or via an implantable chamber or peripheral intravenous infusion. Patients were reviewed regularly 
every two weeks in order to ensure the good compliance with treatment requirements. Furthermore, a regular PSA test ensured the effectiveness of the treatment. The main criterion of assessment was the average time before the development of resistance to castration. The secondary criteria included the clarification of the various therapeutic modalities undertaken, their tolerances and their interests in terms of quality of life and comfort. SPSS statistics version 21.0 software enable us to perform statistical analysis of data. Clinical response was assessed by RECIST 2000 criteria. No clear consent was got from our patients in the study for data was collected on anonymous basis and on cases that provide us with information confidentiality.

\section{Results}

\subsection{Survey Population Features (Table 1)}

Our study was more retrospective than prospective and the majority of patients was followed up in a long term. However, results help us improve the care of patients with prostate cancer in Ivorian context.

Table 1. Clinical and pathological features of the sample population.

\begin{tabular}{|c|c|c|c|}
\hline & & $\begin{array}{l}\text { Number of } \\
\text { patients (n) }\end{array}$ & $\begin{array}{c}\text { Percentage } \\
(\%)\end{array}$ \\
\hline \multirow{3}{*}{$\begin{array}{c}\text { Performance } \\
\text { Status }\end{array}$} & 1 & 28 & 33.33 \\
\hline & 2 & 46 & 54.76 \\
\hline & 3 & 10 & 11.90 \\
\hline \multirow{4}{*}{ Features } & Dysuria & 7 & 8.33 \\
\hline & Pollakiuria & 17 & 20.24 \\
\hline & Bleeding & 5 & 5.95 \\
\hline & Bone pain & 55 & 65.48 \\
\hline \multirow{4}{*}{$\begin{array}{c}\text { Initial } \\
\text { metastatic site }\end{array}$} & Bone & 65 & 77.38 \\
\hline & Liver & 4 & 4.76 \\
\hline & Lung & 13 & 15.48 \\
\hline & Brain & 2 & 2.38 \\
\hline \multirow{3}{*}{ PSA rate } & $<50$ & 15 & 17.86 \\
\hline & {$[50-100]$} & 47 & 55.95 \\
\hline & $>100$ & 22 & 26.19 \\
\hline \multirow{2}{*}{ Histology } & only Adenocarcinoma & 78 & 92.86 \\
\hline & Adenocarcinoma $+\mathrm{CNE}$ & 6 & 7.14 \\
\hline \multirow{3}{*}{ Gleason score } & $<7$ & 17 & 20.24 \\
\hline & 7 & 29 & 34.52 \\
\hline & $>7$ & 38 & 45.24 \\
\hline \multirow{3}{*}{$\begin{array}{c}\text { Previous } \\
\text { therapeutics }\end{array}$} & LH-RH analogs + Anti-androgen (BAC) & 31 & 36.90 \\
\hline & LH-RH analogs (BAI) & 42 & 50 \\
\hline & Pulpectomy & 11 & 13.01 \\
\hline
\end{tabular}


During the study period, 84 patients with an average age of 61 met our inclusion criteria. Following the consultation, it has been noticed that seventy-four patients of the sample population (representing 88.09\%) had a Performance Status less than or equal to 2. Various symptoms were noticed and they were dominated by lower urinary tract symptoms and bone pain. $77 \%$ of the patients suffered from bone metastasis. Histopathologically, the most common type remains adenocarcinoma. In most cases, Gleason score was greater than 7 (45\% of the cases). Castration by using LH-RH analogs whether or not combined with an anti-androgen drug was common practice.

\subsection{Period before the Development of Resistance and the Therapeutic Strategy (Table 2, Table 3)}

Development of resistance to castration appeared after an average period of 9 months. Docetaxel and Prednisone Chemotherapy was the dominant therapeutic

Table 2. Average time before development of resistance.

\begin{tabular}{ccc}
\hline Month & Number of patients (n) & Percentage (\%) \\
\hline$[3-6[$ & 5 & 6 \\
{$[6-9[$} & 16 & 19 \\
{$[9-12[$} & 43 & 51 \\
{$[12-15[$} & 13 & 15 \\
{$[15-18[$} & 4 & 5 \\
$\geq 18$ & 3 & 4 \\
Total & 84 & 100 \\
\hline
\end{tabular}

Average time before resistance development: 9 months.

Table 3. Therapeutics after -resistance to castration.

\begin{tabular}{|c|c|c|c|}
\hline & & $\begin{array}{l}\text { Number of } \\
\text { patients ( } n)\end{array}$ & Percentage (\%) \\
\hline \multirow{2}{*}{ Chemotherapy } & Docetaxel-Prednisone & 59 & 70.24 \\
\hline & Weekly used of Taxol & 6 & 7.14 \\
\hline \multicolumn{2}{|c|}{ Estramustine acetate } & 0 & 0 \\
\hline \multicolumn{2}{|c|}{ Abiraterone acetate } & 8 & 9.5 \\
\hline \multicolumn{2}{|c|}{ Exclusively symptomatic treatment } & 11 & 13.09 \\
\hline \multicolumn{2}{|c|}{ Enzalutamide } & 0 & 0 \\
\hline \multicolumn{2}{|c|}{ Sipuleucel -T } & 0 & 0 \\
\hline \multicolumn{2}{|c|}{ Estrogens } & 0 & 0 \\
\hline \multicolumn{2}{|c|}{$\begin{array}{l}\text { Continuation of the previous } \\
\text { androgen blockage treatment }\end{array}$} & 73 & 86.90 \\
\hline \multirow{3}{*}{ Adjuvant therapy } & Biphosphonate & 59 & 70.23 \\
\hline & Daunosumab & 0 & 0 \\
\hline & RT Palliative & 3 & 3.57 \\
\hline
\end{tabular}


method (70\% of the cases). Furthermore, the continuation of hormone therapy was performed for $86.9 \%$ of the patients. Very few patients (9.5\% of them) were treated by Abiraterone Acetate. Bisphosphonates was often proposed to patients suffering from bone metastasis as adjuvant therapy.

\subsection{Evaluation and Safety Profile of Therapeutics Undertaken (Tables 4-6, Figure 1)}

Significant clinical and biological gains were noticed mainly during specific post-therapeutic treatment. Moreover an increase of the PSA rate was observed in about 9 months. Toxicities were more often hematologic, digestive and skins disorders. Grade 2 neutropenia, vomiting alopecia, representing respectively $62 \%, 17 \%$ and $94 \%$ of the cases were the common issues. Nine months after the treatment, 32 patients (54.24\% of cases) were still alive. A high rate of mortality was noticed among patients who received a purely symptomatic approach.

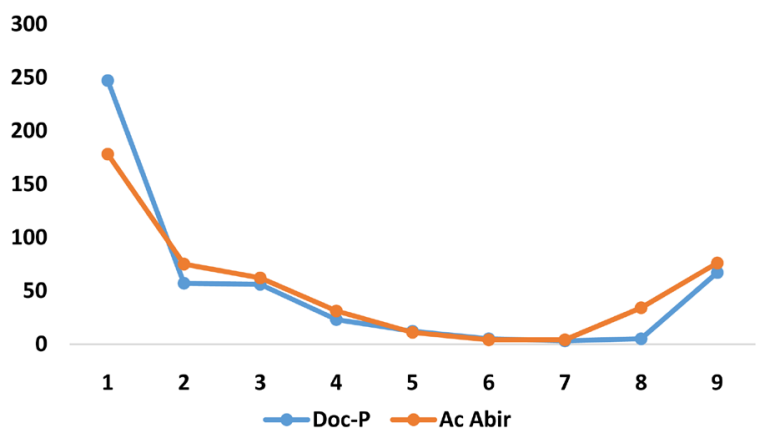

Figure 1. Evolution of PSA average rate during treatment (Dose by month). Ac Abir: Abiraterone Acetate; Doc-P: Docetaxel-Prednisone.

Table 4. Advantages of clinical based symptomatology therapy.

\begin{tabular}{ccccc}
\hline & \multicolumn{3}{c}{ After specific treatment and biphosphonates } \\
\cline { 2 - 4 } & Dysuria & Pollakiuria & Hematuria & Bone pain \\
\hline Chemotherapy (Doc-P) & $2.3 \%$ & $6 \%$ & $1 \%$ & $8 \%$ \\
Abiraterone Acetate & 2.8 & $7 \%$ & $0 \%$ & $7 \%$ \\
Exclusively symptomatic therapy & $4 \%$ & $13 \%$ & $3 \%$ & $29 \%$ \\
\hline
\end{tabular}

Doc-P: Docetaxel-Prednisone.

Table 5. Profile tolerance of chemotherapy.

\begin{tabular}{ccccccccc}
\hline \multirow{2}{*}{ Protocols } & \multicolumn{7}{c}{ Toxicities } & \multicolumn{2}{c}{$\begin{array}{c}\text { Evolution } \\
\text { Haematology }\end{array}$} & \multicolumn{2}{c}{ Digestive } & Skin & $\begin{array}{c}\text { BC } \\
\text { of toxicities }\end{array}$ \\
\cline { 2 - 7 } & Neu & An & Th & Diarrhoea & Vomiting & Alopecia & and/or BL \\
\hline DOC-P & $62 \%$ & $70 \%$ & $3 \%$ & $4 \%$ & $17 \%$ & $94 \%$ & $52 \%$ & Favourable \\
weekly TAXOL & $51 \%$ & $68 \%$ & $0 \%$ & $7 \%$ & $9 \%$ & $89 \%$ & $49 \%$ & Favourable \\
Ac. Ab & $37 \%$ & $69 \%$ & $17 \%$ & $0 \%$ & $5 \%$ & $0 \%$ & $100 \%$ & Favourable \\
\hline
\end{tabular}

Ac Abir: Abiraterone Acetate; bDoc-P: Docetaxel-Prednisone; Neu: Neutropenia; An: Anémia; Th: Thombocytopenia. 
Table 6. Survival after nine months of treatment since the development of resistance.

\begin{tabular}{ccccc}
\hline & Survivor & Lost to follow up & Dead \\
\hline $\begin{array}{c}\text { Nine months of } \\
\text { treatment since } \\
\begin{array}{c}\text { the development } \\
\text { of resistance }\end{array}\end{array}$ & Deekly-Taxol $(\mathrm{n}=6)$ & $2(33.33 \%)$ & $1(16.67 \%)$ & $3(50 \%)$ \\
& $\begin{array}{c}\text { Purely Abir }(\mathrm{n}=8) \\
\text { approach. }(\mathrm{n}=11)\end{array}$ & $3(37.50 \%)$ & $1(12.50 \%)$ & $4(50 \%)$ \\
\hline
\end{tabular}

Ac Abir: Abiraterone Acetate; Doc-P: Docetaxel-Prednisone.

\section{Discussion}

Hormone therapy by total or partial androgen blockage remains the standard therapy for metastatic prostate cancers [9]. The inevitability of resistance development as described in other studies is confirmed. Indeed, resistance is developed after an average period of 9 months since the setting of the initial hormonal treatment. This average period, which is quite short as compared to western series, could be explained by the aggressiveness of prostate cancer from black African subject (patients are young, higher Gleason rate, permanent lymph node extension, frequent metastasis) [8]. Poor adherence and poor compliance to the initial hormonal therapy, the existence of several metastatic sites could also explain the early development of resistance to the treatment.

Most of our hormone-resistant patients were treated by combining Docetaxel and prednisone chemotherapy, resulting in clinical and biological satisfaction. Indeed, this is the used protocol which has proved to be effective in improving the overall survival rate in two randomized studies (SSOG 9916 and TAX 327 studies [9] [10]). While very few patients in our series were treated by Abiraterone acetate due to failure to get access to this molecule; in Western series patient under the same molecule get biological responses by about $50 \%$.

The main toxicities were similar to other series, they were moderate and decreased spontaneously or sometimes under symptomatic treatment [11]. No deaths linked to the toxicities of the treatment and no interruption of the treatment were observed.

The rise of PSA rate observed after 9 months shows the development of a resistance to the chemotherapy which led to other therapies including cabazitaxel, Enzalutamide, and Spilucel T [11].

\section{Conclusion}

In a cohort of 84 patients relatively young with metastatic prostate adenocarcinoma initially treated by hormone therapy (chemical or surgical), resistance occurred within a relatively short time reflecting the aggressiveness of the black African patient suffering from prostate cancer. Combining Docetaxel and prednisone chemotherapy was the common used therapeutic modality in our series and this led to a clinically and biologically significant gain with an acceptable safety profile. However, a chemo-resistance could quickly appear, opening door 
to other therapies including anti-androgen of second generation or second-line chemotherapy. These effective drugs are still largely inaccessible to our patients not only because of their extremely high costs but also of their non-availability in our context. This work sounds like a plea towards all stakeholders involved in the management of prostate cancer, namely political authorities, health professionals and the population.

\section{Conflicts of Interest}

The authors declare no conflicts of interest regarding the publication of this paper.

\section{References}

[1] Tengue, K., Kpatcha, T.M., Botcho, G., Leloua, E., et al. (2016) Profil épidémiologique, diagnostique, thérapeutique et évolutif du cancer de la prostate au Togo. African Journal of Urology, 22, 76-82. https://doi.org/10.1016/j.afju.2015.06.006

[2] Ammani, A., et al. (2007) Profil épidémiologique du cancer de la prostate dans le service d'urologie de l'hopital Mohammed V de Rabat. Journal Marocain d Urologie, 5, 11-14.

[3] Mottet, N., Costa, P., Le Pellec, L., Louis, J.F. and Navratil, H. (1995) Cancer de prostate: Physiologie et développement cellulaire. Progrès en Urologie, 5, 39-47.

[4] Fournier, G., Valeri, A. and Cussenot, O. (2004) Prostate Cancer Treatment. Annales d Urologie, 38, 225-258. https://doi.org/10.1016/j.anuro.2004.06.004

[5] Cabrespine, A., Guy, L., Chollet, P., Debiton, É. and Bay, J.O. (2004) Mécanismes moléculaires impliqués dans l'hormonorésistance du cancer de la prostate. Bulletin du Cancer, 91, 747-757.

[6] Alexandre, I. and Rixe, O. (2007) Hormone-Refractory Prostate Cancer. Annales d Urologie, 41, 47-55. https://doi.org/10.1016/j.anuro.2007.02.003

[7] Niang, L., Ndoye, M., Ouattara, A., Jalloh, M., Labou, M., Thiam, I., Kouka, S.C., Diaw, J.J. and Gueye, S.M. (2013) Management of Prostate Cancer in Senegal: What Is Being Done? Progrès en Urologie, 23, 36-41.

https://doi.org/10.1016/j.purol.2012.09.002

[8] Ahmed, E.I., Zehr, J.L., Schulz, K.M., Lorenz, B.H., DonCarlos, L.L. and Sisk, C.L. (2008) Pubertal Hormones Modulate the Addition of New Cells to Sexually Dimorphic Brain Regions. Nature Neuroscience, 11, 995-997.

https://doi.org/10.1038/nn.2178

[9] Petrylak, D.P., Tangen, C.M., Hussain, M.H., Lara P.N., et al. (2004) Docétaxel and Estramustine Compared with Mitoxantrone and Prednisone for Advanced Refractory Prostate Cancer. New England Journal of Medicine, 351, 1513-1520. https://doi.org/10.1056/NEJMoa041318

[10] Tannock, I.F., de Wit, R., Berry, W.R., Horti, J., Pluzanska, A., Chi, K.N., et al. (2004) Docétaxel plus Prednisone or Mitoxantrone plus Prednisone for Advanced Prostate Cancer. New England Journal of Medicine, 351, 1502-1512. https://doi.org/10.1056/NEJMoa040720

[11] Ouzaid, I., Ravery, V., Pouessel, D. and Culine, S. (2013) Novel Agents for the Therapy of Castration-Resistant Prostate Cancer: Overview of Pivotal Studies and New Strategies to Come. Progrèsen Urologie, 23, 1-7. 